\section{Healthier lifestyles key to solving childhood obesity epidemic}

ith studies revealing that childhood obesity

has tripled in the United States since 1980, UC researchers have taken a leading role in developing educational resources and outreach programs to reverse this alarming trend.

"We must change community environments so they are more supportive of healthy lifestyles, or we will not be able to address this problem," says Joanne Ikeda, UC Cooperative Extension (UCCE) nutrition education specialist and co-director of the UC Berkeley Center for Weight and Health.

According to a recent American Medical Association report, nearly 9 million U.S. children ages 6 to 9 are now seriously overweight. "This trend has contributed to troubling increases in the incidence of serious, chronic diseases such as diabetes and other weight-related illnesses in children," says Pat Crawford, UCCE nutrition specialist and Center co-director. "Not surprisingly, this mirrors similar trends in adults" (see pages 3,8 ).

Furthermore, obesity rates are rising fastest among low-income, ethnic minorities including African American, Native American and Latino children. The multiethnic Oakland school district, for example, recently took the unusual step of hiring California's first school nurse whose sole assignment is to educate students, parents and teachers about diabetes.

To focus on environmental, family-based and clinical strategies, the Center is cohosting the 2003 California Childhood Obesity Conference in San Diego in early January 2003, with the California Department of Health Services. In addition to pursuing important pediatric nutrition research, UC scientists and advisors have offered workshops around the state and developed an array of resources to promote healthier eating habits and lifestyles among children.

Community resource kits. "Children and Weight: What Communities Can Do" is a "how-to" guide for community leaders who want to start a coalition for preventing weight problems in children. The philosophy behind the kit, which was developed by Ikeda and Crawford with the California Fit Women, Infants and Children (WIC) Project, is that the best way to slow or halt excessive weight gain in children is to create environments that provide them with more opportunities to eat well and be physically active.

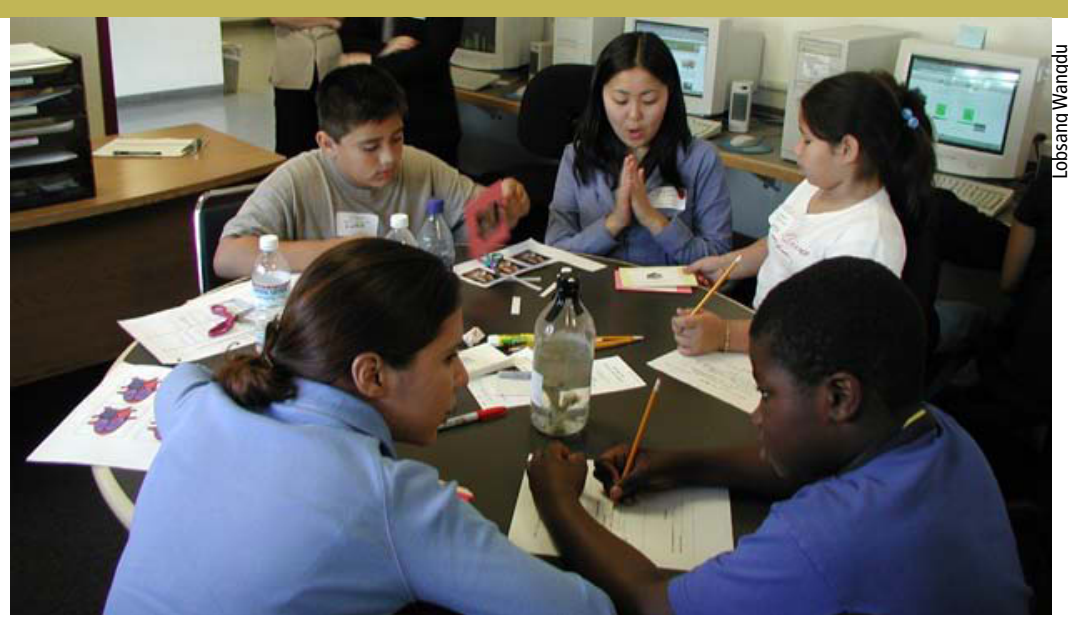

To address childhood weight issues positively, UC Cooperative Extension advisors created the Nutri-Link program, which uses computers and hands-on activities to teach youth about healthful eating. Undergraduate research apprentices in the UC Berkeley School of Public Health helped pilot test the program at an Oakland YMCA last spring.

The kit contains the essentials for establishing community coalitions, helping groups set goals, formulating action plans, and staying focused and energized, says Kirstin Siemering, UC Berkeley graduate student and development team member. "Often the hardest part in forming a coalition is getting started, so we focused on the nuts and bolts of organizing the first five meetings, and made the materials as userfriendly as possible." A similar kit targeting health professionals was released in early 2000.

Nutrition and computers. Last June, UCCE Alameda County child/youth program coordinator Jo Ann Johnson rolled out the Nutri-Link program, a Web-based after-school program designed to help youth learn about healthful eating and physical activity in order to reduce the risk of chronic diseases. Youth acquire computer and critical-thinking skills via hands-on science activities and game play designed to reach a multicultural audience. "It is easy to teach nutrition, but not as easy to influence behavior nor guarantee access to healthy foods," Johnson says. "Nutri-Link reinforces the cornerstones of public health nutrition: moderation, variety and balance."

Weight acceptance television show. Ikeda worked closely with producers of "A Walk In Your Shoes," a television show geared to early teenagers, on a half-hour segment on weight discrimination. One goal was to help prevent the psychological trauma that many overweight children experience. The show was first broadcast on The $\mathrm{N}$ and Nickelodeon channels last October, accompanied by lesson plans for educators. $\quad$ Editors
For more information, go to: www.cnr.berkeley.edu cwh 